\title{
Effects of GLP-1 analogues in the treatment of a population with DM2
}

Ivo, C.; Silva, J.; Simões, H.; Lopes, L.; Passos, D.; Marcelino, M.; Jácome de Castro, J. - Endocrinology Service- Hospital das Forças Armadas - Portugal

GLP-1 analogues (aGLP1) are a new class of anti-diabetic agents, administered subcutaneously for the treatment of Diabetes Mellitus type 2 (DM2). In the Portuguese market, there are two aGLP1 currently available: Liraglutide (once-daily administration) and Exenatide (once-weekly administration). They mimic the GLP-1, produced in the small intestine, stimulated by foods at this region, increasing the production of insulin, decreasing the satiety and slowing gastric emptying.

Therefore, they induce insulin production and decreased satiety and gastric emptying. This pharmacological class have shown benefit in metabolic control (0.5 to $1.5 \%)$ and weight $(-1.5$ to $3,4 \mathrm{Kg})$.

AIMS: Impact assessment of aGLP1 in patients with DM2 followed in diabetes clinic.

METHODS: Retrospective study of diabetic patients followed in clinic, using aGLP1, since January 2014 to December 2015. Their were evaluated: demographic data, the anti-diabetic medication used before the introduction of the drug, metabolic control and the weight on the 0, 3 and 6 months(M). Data were analysed according to descriptive statistical methods.

\section{RESULTS}
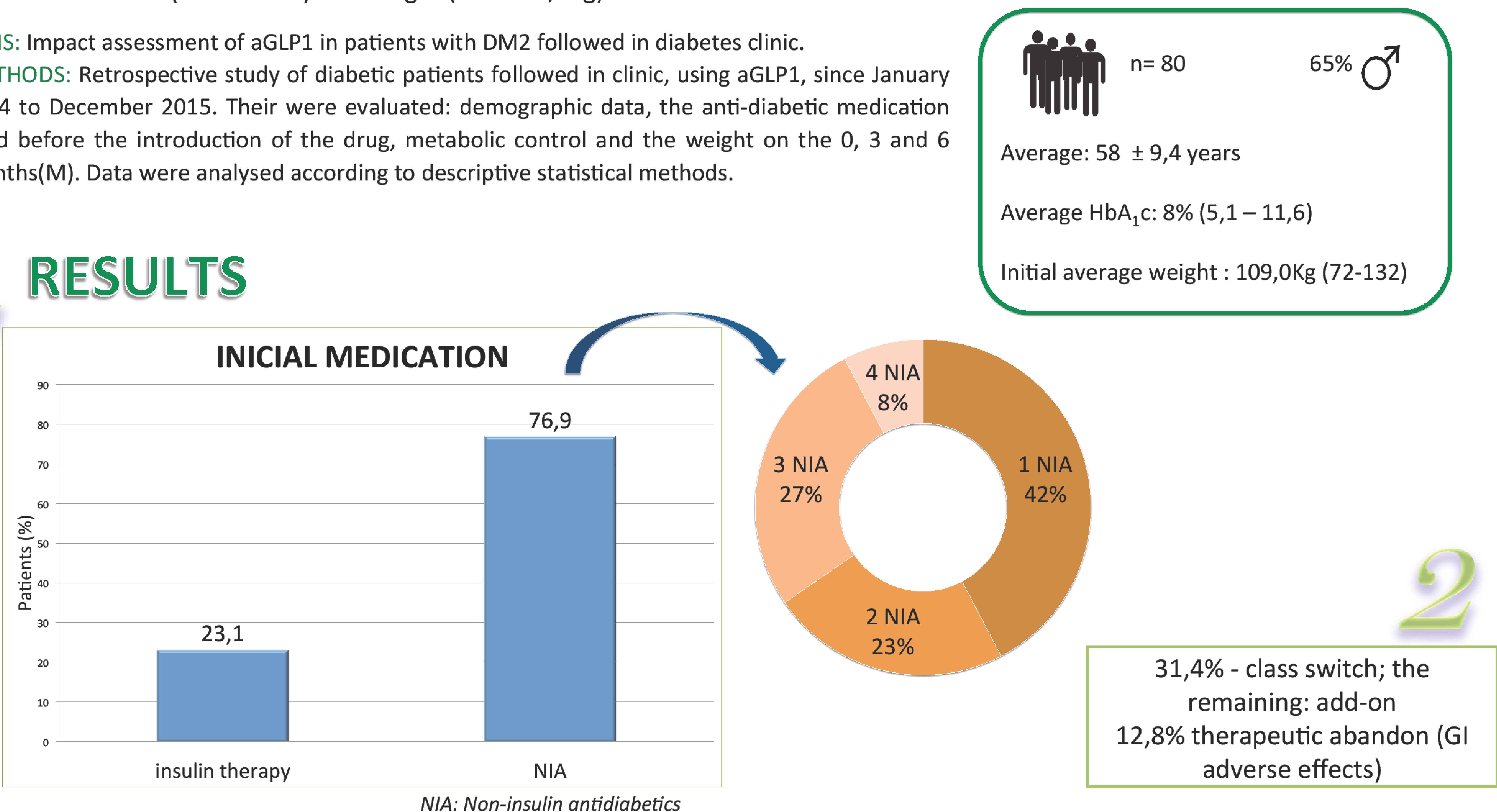

Average Weigth reduction $(\mathrm{Kg})$

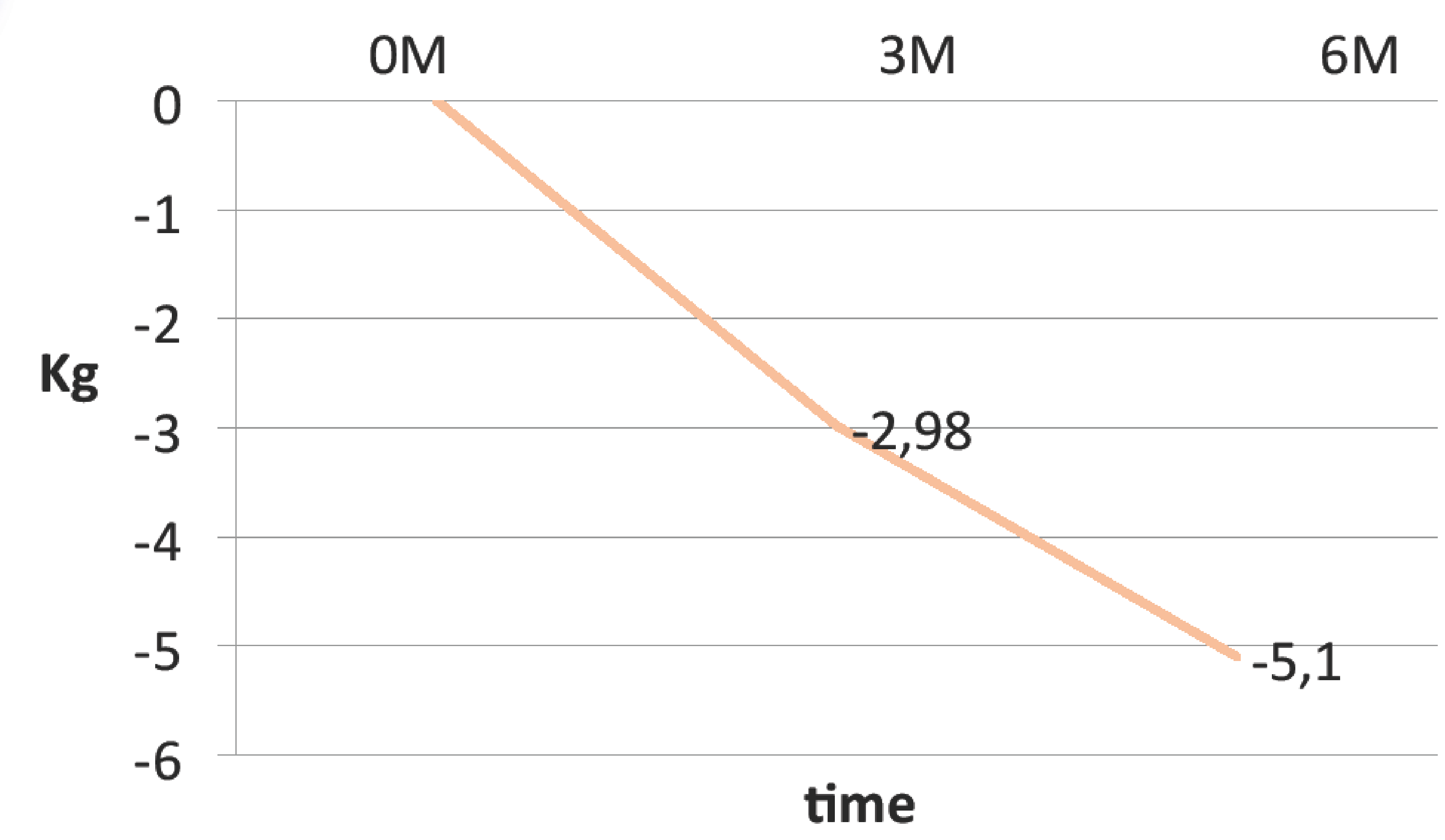

$0 \%$ increase of weight and $10 \%$ retained weight

\section{Average $\mathrm{HbA1c}$ variation}

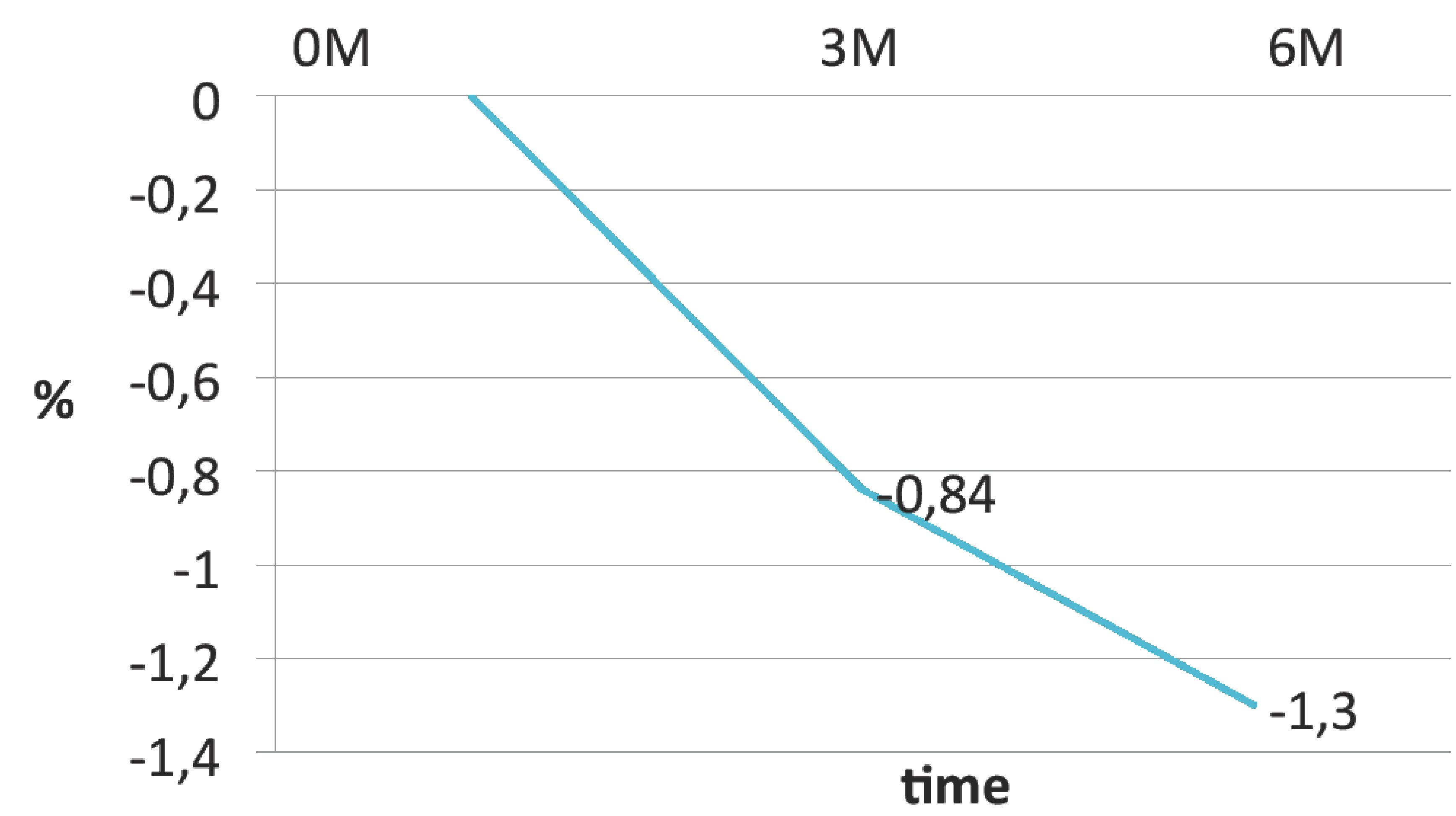

HbA1c was increased in $15 \%$ of patients

Conclusion: The profile of patients who started this pharmacological class was mostly patients on monotherapy and obese, which shows the potential of these drugs on improvement of the metabolic control and reducing weight. Reductions in HbA1c were described between $0.5-1.5 \%$ 1. Our patients had similar results: 3months to reductions of $-0.84 \%(-3.0$ and +1.7$)$ and $6 \mathrm{months}$ of $-1.3 \%(-3.8+2.5)$. Data also suggest weight reductions between $1,5-3,4 \mathrm{Kg} 2$. Afther 6 months, our patients have lost $5,1 \mathrm{Kg}(-16$ to +2$)$. Regarding adverse effects, GI symptoms may occur in $15 \%$ of patients, more frequently in the first weeks of treatment. $12,8 \%$ of our patients have stopped therapy due to this symptoms. Long term results are necessary to improve this data.

Bibliography:

1. Blevins T, et al. J Clin Endocrinol Metab. 2011;96:1301-1310; 2. Astrup et al Lancet 2009 ; 3.Garber et al Diabetes Obes Metab 2011:13:348-56 